\title{
DESIGN AND FABRICATION OF 3D PRINTER
}

\author{
Ativya Gupta \\ Department of ME \\ SRMCEM, Lucknow, Uttar Pradesh
}

Garima

Department of ME

SRMCEM, Lucknow, Uttar Pradesh
Harshit Srivastava

Department of ME

SRMCEM, Lucknow, Uttar Pradesh

\author{
Er. Sunil Kumar Yadav \\ (Asst. Professor) \\ Department of Mechanical Engineering (ME) \\ Shri Ramswaroop Memorial College of Engineering and Management \\ Lucknow, Uttar Pradesh, India
}

\begin{abstract}
The project entitled Design and Fabrication of a 3D Printer defines about the different types of $D$ printer being used in the market and the final analysis of the various input and output parameters that has been taken into consideration.

It also describes about the present application and the future scope of the 3D Printer.

A 2D-sketch of butterfly was been prepared in the Solidworks software which was further extruded into its 3D-model. After converting the 2D sketch into 3D model the file was saved and transferred in the STL (Standard Tessellation Language) file format for the final layer by layer manufacturing in the 3D printer. Fused Deposition Modelling (FDM) type of 3D printer is been used in the project which does the modelling by depositing the filament through heated nozzle layer by layer on the heated plate to form the final object.

Thus taking the input parameter as the Nozzle diameter, travel speed and layer height we considered the output parameter as Marching time and did our analysis using Design OF Experiments (DOE).

The results after the analysis were like the more nozzle diameter we will use the less machining time will be required with increased layer height and travel speed though with more nozzle diameter the quality of the product would vary a bit but it can be accepted if not much précised or complex design is required. Similarly, the less diameter would require more machining time with less layer height and less travel speed, though the quality of the product will be excellent normally also and for more complex and intricate designs as well.
\end{abstract}

Keywords: 3D Printer, fabrication, analysis, Design of Experiments, Taguchi Method, travel speed, nozzle diameter, layer height, machining time

\section{INTRODUCTION}

A $3 \mathrm{~d}$ printer is an additive manufacturing technique where 3D objects and parts are made by the addition of multiple layers of material. It can also be called as rapid prototyping. It is a mechanized method where 3D objects are quickly made as per the required size machine connected to a computer containing blueprints of any object.
The additive method may differ with the subtractive process, where the material is removed from a block by sculpting or drilling. The main reason to use $3 \mathrm{~d}$ printer is for $90 \%$ of material utilization, increase product life, lighter and stronger. 3D printing is efficiently utilized in various fields such as aerospace, automobile, medical, construction and in manufacturing of many household products.

3D Printer is more useful and reliable than our conventional manufacturing processes. The process of 3D printer does not require any permanent guidance as in conventional method such as moulding, machining etc.

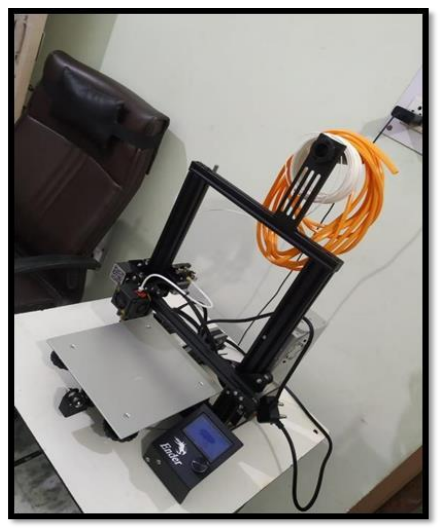

\section{- HISTORY}

The 3D printing innovation is not a new concept as many think. When FDM (fused deposition modelling) licenses had expired in 2009, the 3D printing became a new innovation topic. What's more, because of which it turned out to be more mainstream, individuals envisioned that FDM was the just a single added substance producing system. Be that as it may, the initial 3D printing procedure was SLA not FDM, and its first patent was recorded in 1980 's. Here is the historical backdrop of 3D printing innovation, from 1980 to today.

In 1980's there was the introduction of 3 primary 3D printing systems. Dr. Kodana was the first person to present layer by layer approach for assembling and furthermore he was the principal individual to create fast prototyping strategy. What's more, he made a progenitor for SLA. He polymerized a photosensitive gum with the assistance of UV light, however, did not succeed. 
Shockingly for Dr. Kodana, the full patent detail was not recorded by him before the one-year due date after the application. the causes of $3 \mathrm{~d}$ printing innovation can be followed from 1983.

During the year 1990's the other 3D printing innovation and processes were emerged during this year. And the introduction of new 3D printer manufacturers and cad tools. 3D systems make their first commercial sale of stereolithography (SLA) system. And the other emerging processes were ballistic particle manufacturing (BPM) patented by William masters, solid ground curing (SGC) was been patented by Itzchak Pomerantz et al.

Furthermore, other developing organizations saw amid the nineties till today - Stratasys, EOS, and 3D systems. The 1990 's were the time of first use of the 3D printer in medical researchers, who consolidated the way of pharmaceutical and 3D printing and opening the chances to numerous clients. In 1992 the patent done on fused deposition modeling was issued to Stratasys, who had developed may 3D printers both for professional and for individuals. The SLA (Stereolithographic) apparatus was Made in this year by 3D systems. The first SLA machine uses A UV laser solidifying photopolymer, and a liquid with the viscosity and color of honey that makes the object layer by layer. This was the first rapid prototyping form that had changed the engineering world and design for ever.

\section{PRINCIPLE OF 3D PRINTER}

The principle of 3D Printer is based on the additive layering of the material on top of each other thus producing the final designed product.

\section{- MODELLING}

The object or the model which has to be printed first it has to designed or modeled using a CAD (computer aided drawing) tool like solid works etc. By the 3D scanner or by the digital camera and a very unique photogrammetry software. These 3D printed models were created with help of the CAD results in the reduction of errors which were found and can be corrected before printing. In manual modelling process of preparing geometric data for $3 \mathrm{~d}$ computer graphics is similar to plastic arts such as sculpting. Based on this data 3-dimentional models of the scanned object can be produced.

After modelling in CAD tool the model often be (in .skp, .dae, $.3 \mathrm{ds}$ or some other format) then it needs to be converted to either a .STL or .OBJ format, to allow the printing software to be able to read it.

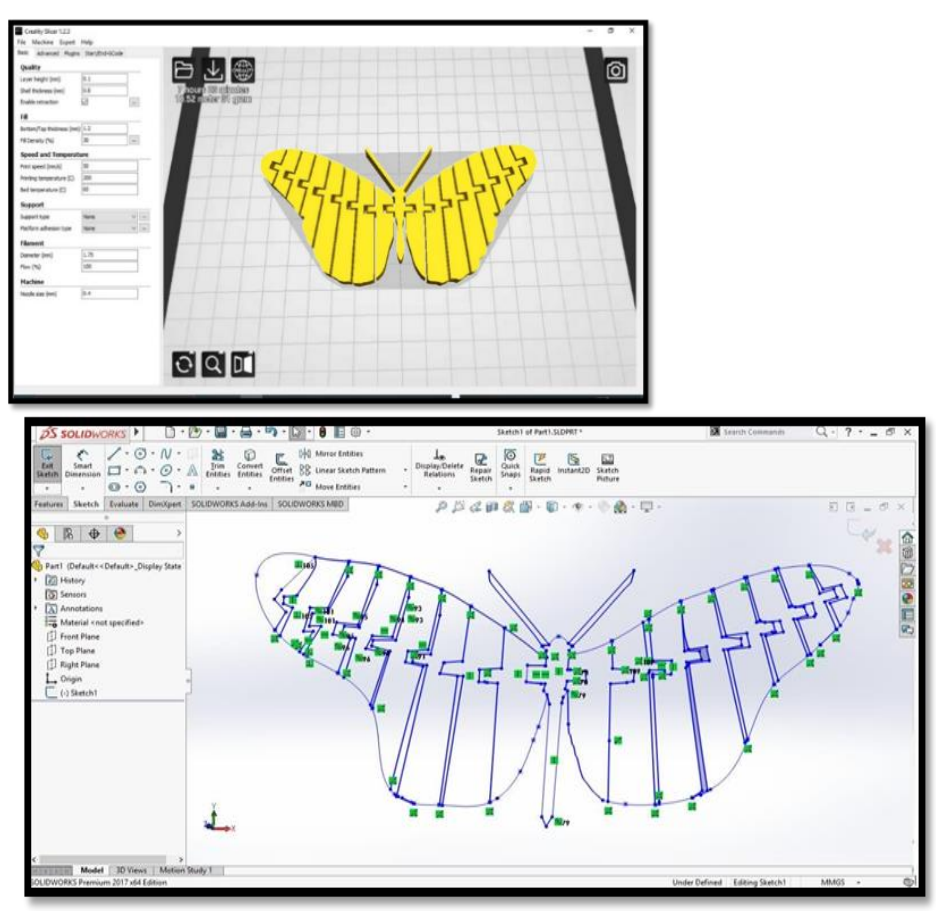

- PRINTING

After the model has been converted to STL, it must be first examined for "errors", this step is called the "fixup". In most of the cad applications produce errors in output STL files errors like sekf intersection, improper holes, face normal has to be corrected. Once the file is converted to STL, the file has to be processed by a software called "slicer" which will convert the model into series of layers and produces a G-code file containing instructions to a specific type of 3D printer.

This G-code file can be printed by using 3D client software (which loads the G- code and uses it to instruct the 3D printer during printing. In practice the client software and the slicer program exist, including Cura, Slic3r, repetier host, pronterface and skeinforge as well as closed source programs like simplify 3D and KISSIicer3D.

3D printer follows the G-code instructions to lay down successive layers of liquid, powder, paper or sheet material to build model from a series of cross sections. The such as plastic, sand, metal etc. can be lused through a print nozzle. These layers, which correspond to the virtual cross sections from the CAD model, are joined or automatically Fused to create the final shape. Depending on what the printer is making, the process could take up to minutes or hours. Printer resolution describes the layer thickness and $\mathrm{X}-\mathrm{Y}$ resolution dots per inch (dpi) or micrometers $(\mu \mathrm{m})$. The layer thickness which can be found can be around the 100gm mark, although some of These machines such as the object connex series and the 3D Systems ProJet series can be very much printed as thin layers as $16 \mu \mathrm{m}$. These resolution of $\mathrm{X}-\mathrm{Y}$ is Comparable to that of laser printers. The particles (3D dots) are around 50 to $500 \mu \mathrm{m}$ 
(510 to 250 Dpi) in diameter. The method of Construction of models can take away from several hours to several days, depending how big the model is, method used, printing speed, and complexity of the model. Typically, the time can be reduced to few hours depending on the type of machine used and size. 3D printers give designers and concept models using a desktop size of $3 \mathrm{D}$ printer.
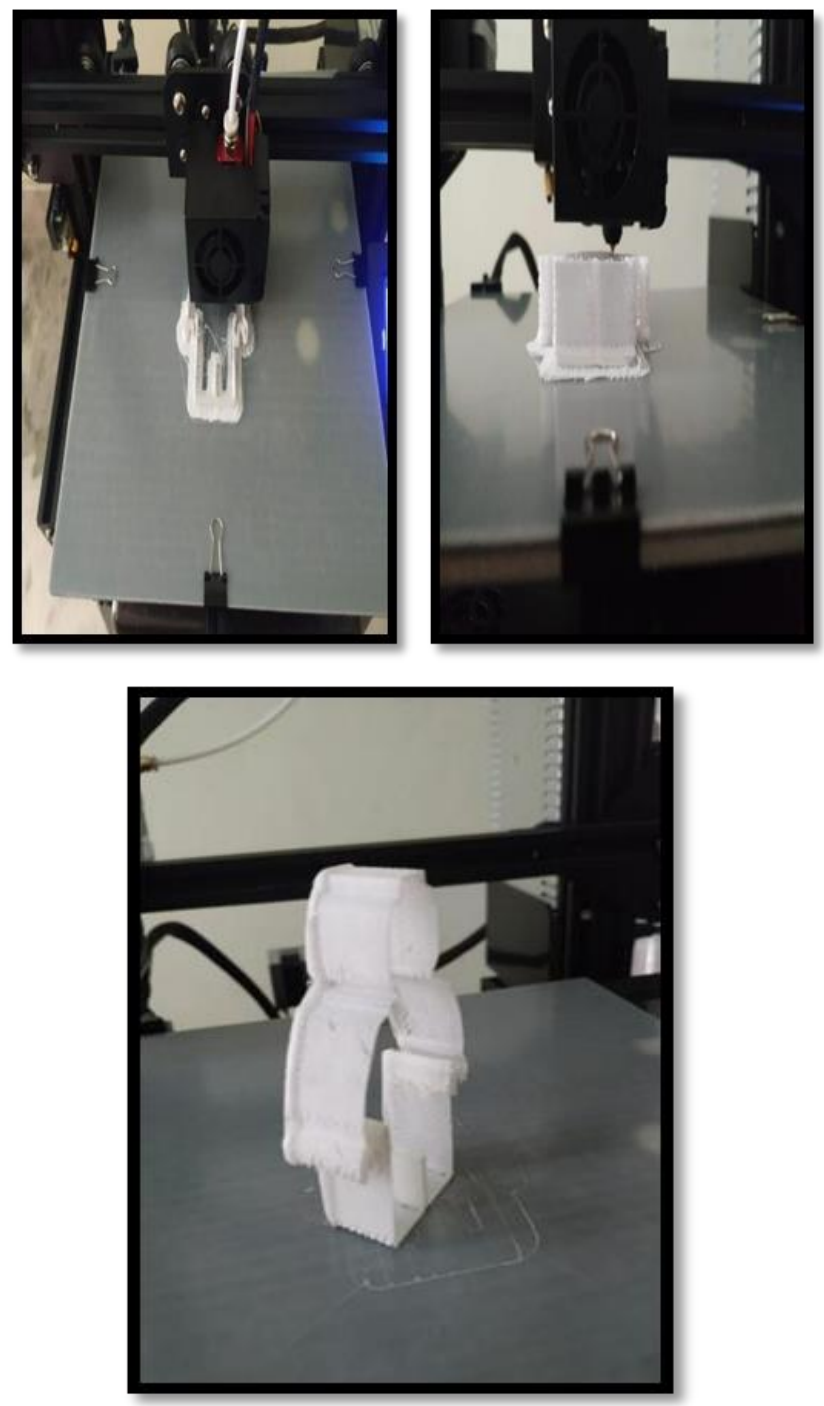

These are the pictures of the model which we designed and printer from our 3D Printing machine.

\section{- FINISHING}

The printer produced resolution is very much sufficient for many of the applications but the printing will be a slightly oversized version of these desired object which can be the standard resolution and then the process of removing material can give greater precision. Some printable polymers allow the surface finish to be smoother and improved using chemical vapor processes.

There are some of the additive manufacturing techniques which are very capable of using multiple materials in these course of constructing parts. These techniques are very much able to print in multiple colours and colour combinations simultaneously. Some printing techniques require internal supports to be built for overhanging features during construction. These supports must be mechanically removed or dissolved after completion of the printing. The commercialized metal 3D printers which very much likely to involve in cutting the metal component of the metal substrate after deposition. The very new process for the GMAW 3D printing which will allow for substrate surface modifications to remove many aluminium components manually with hammer.

\section{CLASSIFICATION OF 3D PRINTER}

The 3D Printer is generally classified into eight categories:

1. Stereolithography (SLA): SLA is the original industrial 3D printing process. SLA printers excels at producing parts with high levels of detail, smooth surface finishes, and tight tolerances. The quality surface finishes on SLA parts, not only look nice, but can aid in the part's function - testing the fit of an assembly,

For example. It's widely used in the medical industry and common applications include anatomical models and microfluidics.

2. Selective laser sintering (SLS): It melts together nylon-based powders into solid plastic. Since SLS parts are made from real thermoplastic material, they are durable, suitable for functional testing, and can support living hinges and snapfits. In comparison to SL, parts are stronger, but have rougher surface finishes. SLS doesn't require support structures so the whole build platform can be utilized to nest multiple parts into a single build-making it suitable for part quantities higher than other 3D printing processes.

3. PolyJet: It is another plastic 3D printing process, but there's a twist. It can fabricate parts with multiple properties such as colors and materials. Designers can leverage the technology for prototyping elastomeric or overmolded parts. If your design is a single, rigid plastic, we recommend sticking with SL or SLS - it's more economical. But if you're prototyping an overmolding or silicone rubber design, PolyJet can save you from the need to invest in tooling early in the development cycle. This can help you iterate and validate your design faster and save you money.

4. Digital light processing: This type of $3 \mathrm{D}$ printing is similar to SLA in that it cures liquid resin using light. The primary difference between the two technologies is that DLP uses a digital light projector screen whereas SLA uses a UV laser. This means DLP 3D printers can image an 
entire layer of the build all at once, resulting in faster build speeds. While frequently used for rapid prototyping, the higher throughput of DLP printing makes it suitable for low-volume production runs of plastic parts.

5. Multi Jet Fusion (MJF): This process is Similar to SLS, Multi Jet Fusion also builds functional parts from nylon powder. Rather than using a laser to sinter the powder, MJF uses an inkjet array to apply fusing agents to the bed of nylon powder. Then a heating element passes over the bed to fuse each other.

6. Fused Deposition Modelling (FDM):

Fused deposition modelling (FDM) is a common desktop 3D printing technology for plastic parts. An FDM printer functions by extruding a plastic filament layer-by-layer onto the build platform. It's a cost-effective and quick method for producing physical models. There are some instances when FDM can be used for functional testing but the technology is limited due to parts having relatively rough surface finishes and lacking strength.

7. Direct Metal Laser Sintering (DMLS):

Metal 3D printing opens up new possibilities for metal part design. The process we use at Protolabs to 3D print metal parts is direct metal laser sintering (DMLS). It's often used to reduce metal, multi-part assemblies into a single component or lightweight parts with internal channels or hollowed out features. DMLS is viable for both prototyping and production since parts are as dense as those produced with traditional metal manufacturing methods like machining or casting. Creating metal components with complex geometries also makes it suitable for medical applications where a part design must mimic an organic structure.

\section{Electron Beam Melting (EBM):}

Electron beam melting is another metal 3D printing technology that uses an electron beam that's controlled by electromagnetic coils to melt the metal powder. The printing bed is heated up and in vacuum conditions during the Build. The temperature that the material is heated to is determined by the material in use.

\section{APPLICATIONS OF 3D PRINTER}

The application of 3D Printer is almost in every field of society, from which some are listed below:

\section{- EDUCATION:}

Every day, more schools are incorporating 3D printing methods into their curriculums. The benefits of 3D printing for education are that it helps better prepare students for their future by allowing students to create prototypes without the need for expensive tooling.

3D printing bridges the gap from ideas and images on a page or screen, allowing for the creation of those ideas/images in the physical, 3-dimensional world.

- PROTOTYPING AND MANUFACTURING: With a traditional injection-molded prototype it might cost hundreds of thousands of dollars and take weeks to produce a single mold. That is highly impractical if you are trying to improve on design with each new iteration. 3D printing technology greatly reduces the lead times required in traditional manufacturing, allowing a prototype to be fabricated in hours, not weeks, and at a fraction of the cost. The automotive and aerospace industries are just 2 industries involved in manufacturing taking advantage of advances in 3D printing technologies.

\section{- MEDICINES:}

In the last several years there have been many 3D printing applications in the world of medicine. They range from bioprinting - where biomaterials such as cells and growth factors are combined to create tissue-like structures imitating their natural counterparts - to medical devices like prosthetics.

3D printed tissues have been developed for pharmaceutical testing as a cost-effective and Ethical means of helping identify the side effects of drugs and validating safe dosages.

\section{- CONSTRUCTION:}

Construction 3D printing offers various technologies that use $3 \mathrm{D}$ printing as the main Way of fabricating buildings or construction components.

Concrete 3D printing has been in development since the 1990s, as a faster and less expensive way of constructing buildings and other structures. Large-scale 3D printers designed specifically for printing concrete can pour foundations and build walls onsite. They can also be used for printing modular concrete sections that are later assembled on the job site.

The first fully completed residential building was constructed in Yaroslavl, Russia in 2017. 600 elements of the walls were printed in a shop and assembled on site, followed by completion of the roof structure and interior decoration for a total area of $298.5 \mathrm{sq}$ meters (3213 sq ft).

\section{- ART AND JWELLERY:}

An unexpected application of 3D printing technology has been in the world of art and jewelry making.

3D printers allow jewelry makers to experiment with designs not possible with traditional jewelry making methods. 3D printing also allows the production of individual, unique pieces of jewelry or customized pieces at a much lower cost, using $3 \mathrm{D}$ printing materials such as PLA (polylactic acid filament), gold or platinum. 
V.

\section{PROBLEMS AND CHALLENGES IN 3D PRINTING:}

- Equipment costs

- Limited materials available

- Post-processing requirements

- Manufacturing costs

- Lack of in-house additive manufacturing resources

- Lack of expertise and/or training among workforce/employees

- Limited repeatability (accuracy from build to build)

- Lack of formal standards

- Lack of proven documentation of additive manufacturing's capabilities

- Software development and capabilities

- Longer production timelines

- Limited recyclability

- Risk of litigation/legal implication

- Data storage requirements

\section{COMPONENTS}

- Stepper Motors.

- Aluminium Columns.

- Heating Pad.

- Extruder.

- Spool Holder.

- Filament.

- Digital Display.

- Nozzle

\section{PRAPOSED METHODOLOGY}

\section{- OBJECTIVE:}

The main objective of our project is to design and fabricate a working model of a 3D-Printer along with that we have also done some analysis also by changing some parameters like travel speed, nozzle dia. and layer height.

- SOLID MODELLING: We have designed a solid model in solidworks software:

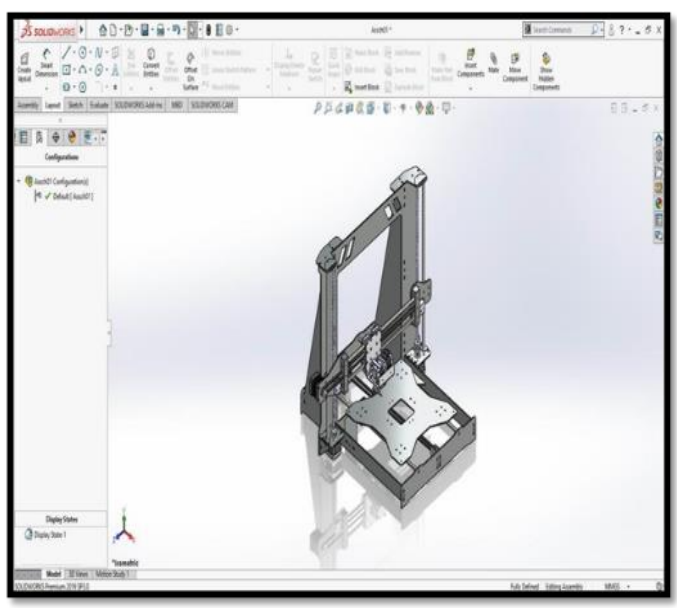

\section{- COMPONENTS AND FINAL ASSEMBLY:}
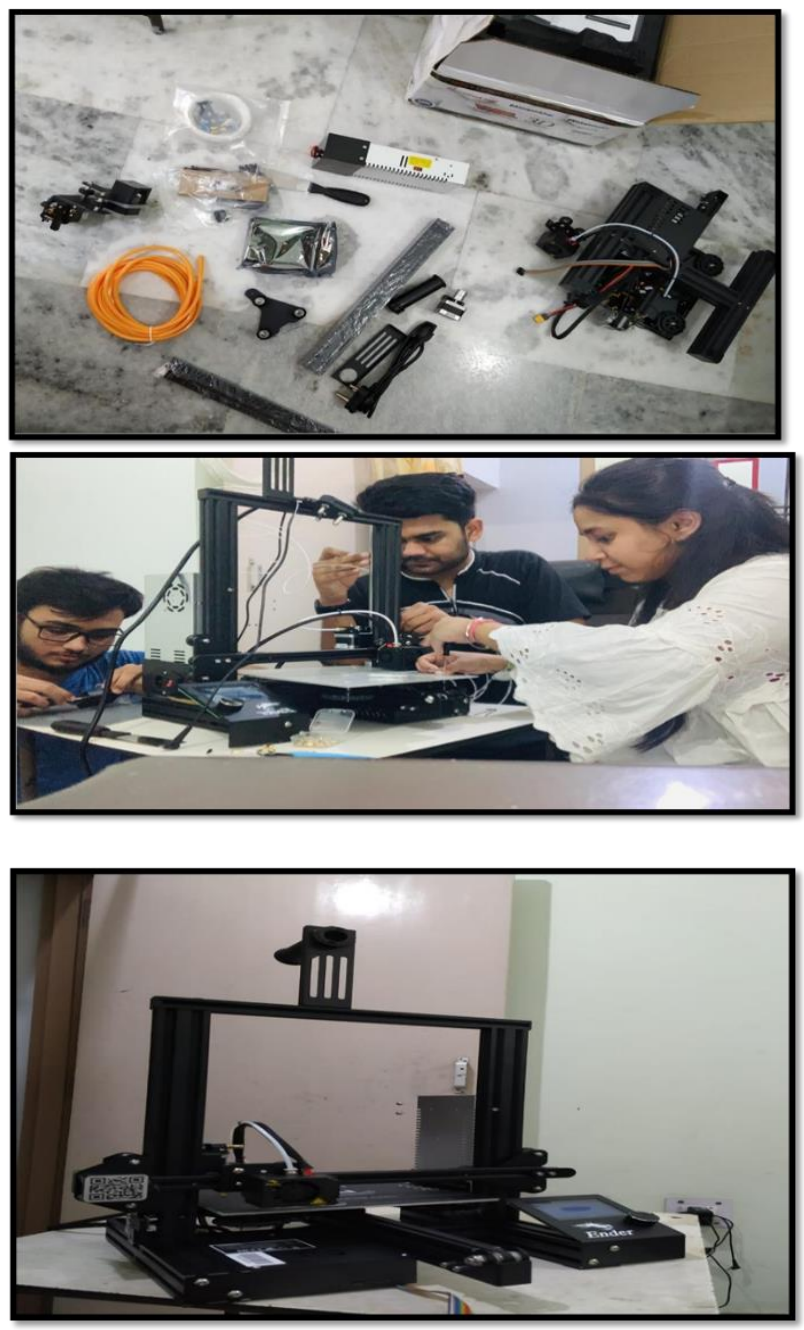

VIII. EXPERIMENTAL ANALYSIS

- We took some parameters of the 3d Printer kept them variable and kept rest of the parameters constant.

- Then by using Design of Experiments we conducted our experiments i.e. by changing the travel speed, nozzle diameter and layer thickness.

- In Design of Experiments we used Taguchi Method to analyse our findings and finally producing the results.

- Minitab Design of Experiments uses the following features to produce results:

$\checkmark$ Catalogues of designed experiments to help you create a design

$\checkmark$ Automatic creation and storage of your design after you specify its properties 
Display and storage of diagnostic statistics to help you interpret the results

Graphs to help you interpret and present the results.

\section{PARAMETERS}

- CONSTANT PARAMETERS:

Parameters like filament diameter, printing temperature, bed temperature, shell thickness were kept constant.

\begin{tabular}{|lc|}
\hline Filament dia. & $1.75 \mathrm{~mm}$. \\
\hline Printing temp. & $200^{\circ} \mathrm{C}$ \\
\hline Bed temp. & $60^{\circ} \mathrm{C}$. \\
\hline Shell thickness. & $0.8 \mathrm{~mm}$. \\
\hline
\end{tabular}

\section{- VARIABLE PARAMETERS:}

We have changed the nozzle diameter, travel speed and layer height of our model through the creality slicer 1.2.3 software.

\begin{tabular}{|c|c|c|c|}
\hline+ & C1 & $\mathrm{C} 2$ & C3 \\
\hline & Layer Height & Nozzle Dia. & Travel Speed \\
\hline 1 & 0.10 & 0.2 & 50 \\
\hline 2 & 0.10 & 0.4 & 150 \\
\hline 3 & 0.10 & 0.6 & 250 \\
\hline 4 & 0.15 & 0.2 & 50 \\
\hline 5 & 0.15 & 0.4 & 150 \\
\hline 6 & 0.15 & 0.6 & 250 \\
\hline 7 & 0.20 & 0.2 & 50 \\
\hline 8 & 0.20 & 0.4 & 150 \\
\hline 9 & 0.20 & 0.6 & 250 \\
\hline
\end{tabular}

- OUTPUT PARAMETER:

We have considered machining time as our output parameter.

\begin{tabular}{|r|}
\hline \multicolumn{2}{|c|}{$\mathrm{C4}$} \\
\hline Machining \\
\hline 13.38 \\
7.12 \\
4.50 \\
9.80 \\
4.51 \\
2.46 \\
7.00 \\
3.43 \\
2.80 \\
\hline
\end{tabular}

By changing the Nozzle dia - By increasing the nozzle dia. Machining time can be reduced.

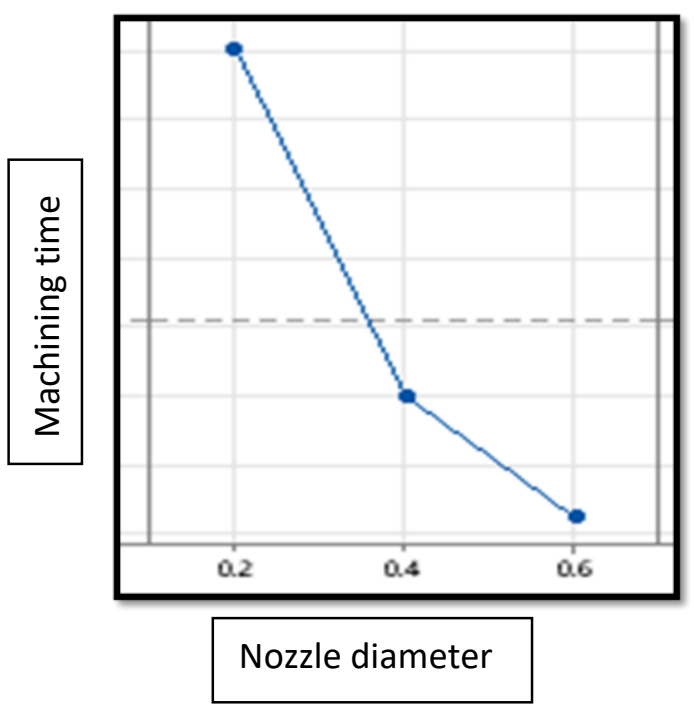

By changing the layer height - By increasing the layer height machining time can be reduced.

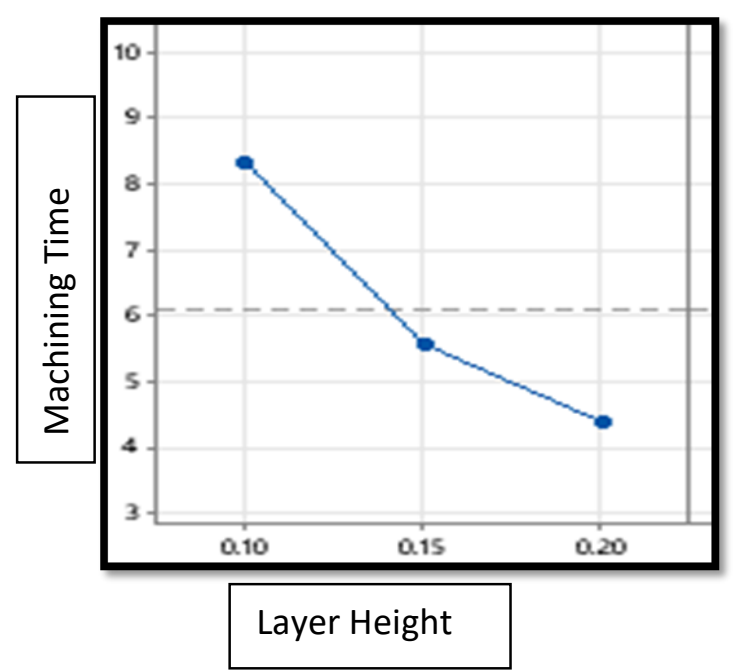

By changing the travel speed - By increasing the layer height machining time can be reduced.

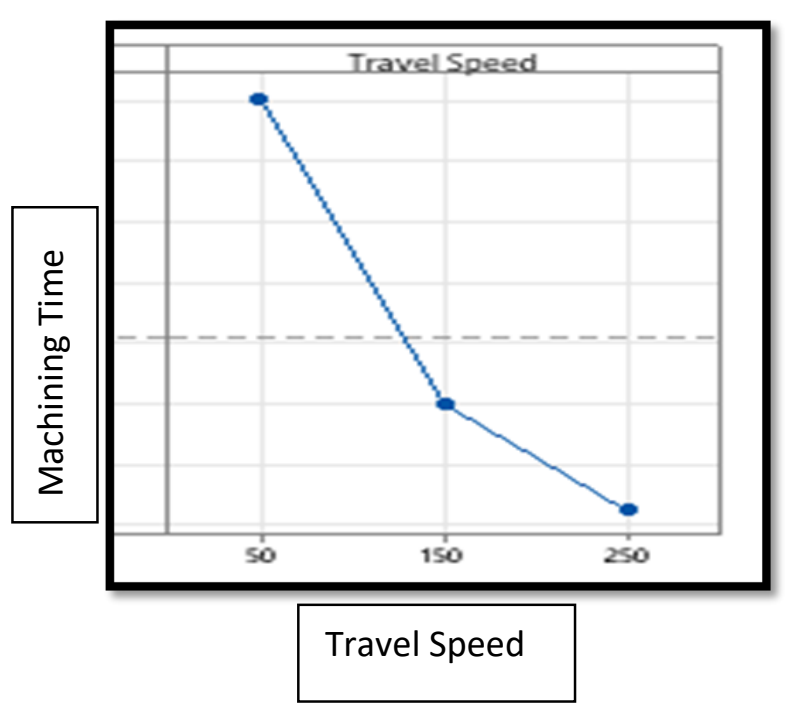


International Journal of Engineering Applied Sciences and Technology, 2021

Vol. 6, Issue 3, ISSN No. 2455-2143, Pages 328-334

Published Online July 2021 in IJEAST (http://www.ijeast.com)

\section{EXPERIMENTAL DATA AND MEAN GRAPH BY TAGUCHI METHOD}

\begin{tabular}{|c|c|c|c|c|}
\hline$\downarrow$ & C1 & $\mathrm{C} 2$ & C3 & $\mathrm{C} 4$ \\
\hline & Layer Height & Nozzle Dia. & Travel Speed & Machining Time \\
\hline 1 & 0.10 & 0.2 & 50 & 13.38 \\
\hline 2 & 0.10 & 0.4 & 150 & 7.12 \\
\hline 3 & 0.10 & 0.6 & 250 & 4.50 \\
\hline 4 & 0.15 & 0.2 & 50 & 9.80 \\
\hline 5 & 0.15 & 0.4 & 150 & 4.51 \\
\hline 6 & 0.15 & 0.6 & 250 & 2.46 \\
\hline 7 & 0.20 & 0.2 & 50 & 7.00 \\
\hline 8 & 0.20 & 0.4 & 150 & 3.43 \\
\hline 9 & 0.20 & 0.6 & 250 & 2.80 \\
\hline
\end{tabular}
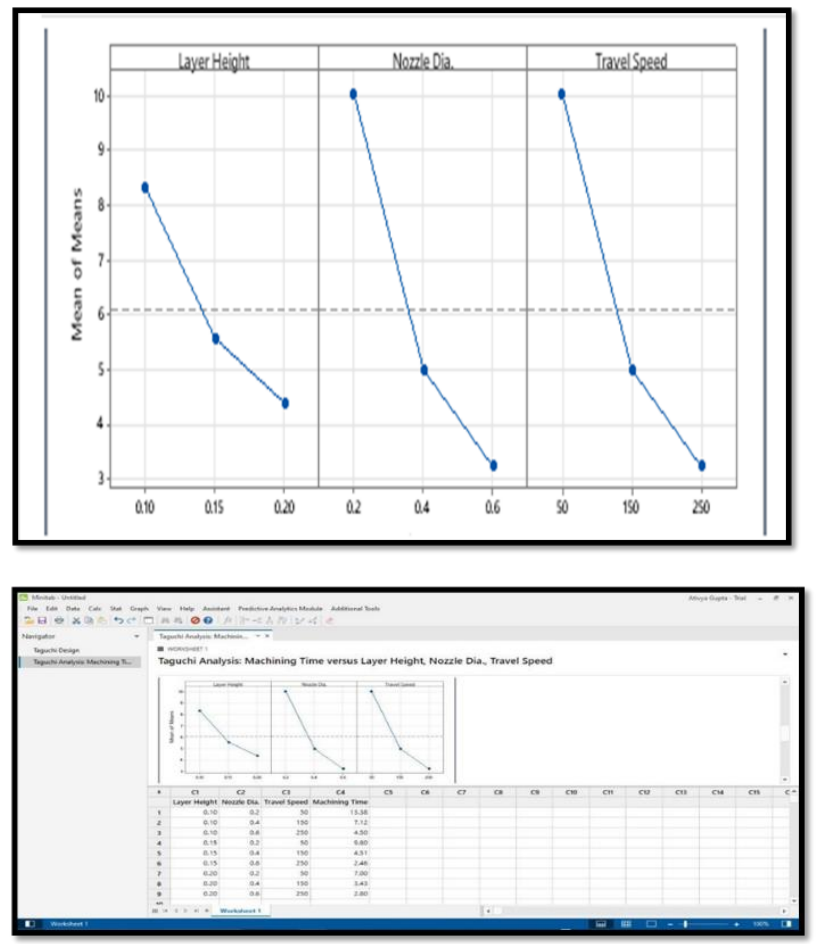

* By increasing the nozzle diameter, layer height and travel speed we can simultaneously reduce the machining time.

\section{CONCLUSION}

It is generally accepted that $3 \mathrm{D}$ printing will be a revolutionary force in manufacturing, whether positive or negative. Despite Concerns over fraud, many companies are already using the technology to repeatedly produce intricate components, for example in automotive and aerospace manufacturing.

There will be major challenges for the conventional manufacturing industry to adapt to these changes. The opportunities for technology and engineering are clearly huge, however, and the creative possibilities in product design and printing material formulation are nearly endless.

Hence in our project we tried to minimize the machining time while changing various parameters like Layer Height, Nozzle Diameter and Travel Speed along with keeping some parameters at constant such as Filament Diameter, Printing Temperature, Bed Temperature, and Shell Thickness.

By varying the variable parameters we came to the conclusion that by increasing the layer height, nozzle diameter and travel speed the machining time will be reduced, similarly by decreasing the value of the same parameters the machining time will be increased.

\section{REFERENCES}

1. https://3dprinting.com/what-is-3d-printing/

2. https://en.wikipedia.org/wiki/3D_printing

3. https://3dprintingindustry.com/3d-printingbasics-free-beginners-guide

4. https://www.zdnet.com/article/everything-youneed-to-know-about-3d-printing- and-its-impacton-your-business/

5. https://www.instructables.com/3D-Design-For3D-Printing/

6. https://www.hubs.com/knowledge-base/keydesign-considerations-3d-printing/

7. https://en.wikipedia.org/wiki/3D_printing_proce sses

8. https://builtin.com/3d-printing

9. https://all3dp.com/1/types-of-3d-printers-3dprinting-technology/

10. https://robu.in/3d-printer-filament-types/

11. https://www.sciencedirect.com/science/article/pi $\mathrm{i} / \mathrm{S} 2214785320320642$

12. https://sci-

hub.mksa.top/10.1016/j.matpr.2020.08.284

13. https://scihub.mksa.top/10.1016/j.matpr.2020.04.905

14. https://scihub.mksa.top/10.1016/j.matpr.2020.08.627

15. https://www.matterhackers.com/news/3dprinter-nozzle-comparison-guide

16. https://www.think3d.in/comparison-of-various3d-printer-nozzles/

17. https://all3dp.com/2/3d-printer-nozzle-sizematerial-what-to-know-which-to-buy/

18. https://ultimaker.com/learn/what-filaments-canbe-used-for-3d-printing

19. https://all3dp.com/1/3d-printer-filament-types3d-printing-3d-filament/

20. https://en.wikipedia.org/wiki/3D_printing_filam ent. 